Journal for ImmunoTherapy of Cancer

\title{
Impact of COVID-19 outbreak on cancer immunotherapy in Italy: a survey of young oncologists
}

Margaret Ottaviano (D) , ${ }^{1,2}$ Marcello Curvietto, ${ }^{3}$ Pasquale Rescigno, ${ }^{4}$ Marianna Tortora, ${ }^{5}$ Giovannella Palmieri, ${ }^{5}$ Diana Giannarelli, ${ }^{6}$ Michele Aieta, ${ }^{7}$ Pasquale Assalone, ${ }^{8}$ Laura Attademo, ${ }^{9}$ Antonio Avallone, ${ }^{10}$ Francesco Bloise, ${ }^{11}$ Davide Bosso, ${ }^{12}$ Valentina Borzillo, ${ }^{13}$ Giuseppe Buono, ${ }^{14}$ Giuseppe Calderoni, ${ }^{15}$ Francesca Caputo, ${ }^{16}$ Giacomo Cartenì, ${ }^{17}$ Diletta Cavallero, ${ }^{11}$ Alessia Cavo, ${ }^{18}$ Fortunato Ciardiello, ${ }^{19}$ Raffaele Conca, ${ }^{7}$ Vincenza Conteduca, ${ }^{20}$ Stefano De Falco, ${ }^{21}$ Marco De Felice, ${ }^{19,22}$ Michelino De Laurentiis, ${ }^{23}$ Pietro De Placido, ${ }^{24}$ Sabino De Placido, ${ }^{5,24}$ Irene De Santo, ${ }^{25}$ Alfonso De Stefano, ${ }^{10}$ Carminia Maria Della Corte, ${ }^{19}$ Rossella Di Franco, ${ }^{13}$ Vincenzo Di Lauro, ${ }^{23,24}$ Antonietta Fabbrocini, ${ }^{12}$ Piera Federico, ${ }^{12}$ Lucia Festino, ${ }^{3}$ Pasqualina Giordano, ${ }^{12}$ Mario Giuliano, ${ }^{5,24}$ Cesare Gridelli, ${ }^{26}$ Antonio Maria Grimaldi, ${ }^{3}$ Michela Lia, ${ }^{27}$ Antonella Lucia Marretta, ${ }^{24}$ Valentina Massa, ${ }^{11}$ Alessia Mennitto, ${ }^{28}$ Sara Merler, ${ }^{29}$ Valeria Merz (iD , ${ }^{30}$ Carlo Messina, ${ }^{30}$ Marco Messina, ${ }^{31}$ Monica Milano, ${ }^{28}$ Alessandro Marco Minisini, ${ }^{32}$ Vincenzo Montesarchio, ${ }^{16}$ Alessandro Morabito (D) ,33 Floriana Morgillo, ${ }^{19}$ Brigitta Mucci, ${ }^{24}$ Lucia Nappi, ${ }^{34}$ Fabiana Napolitano, ${ }^{24}$ Immacolata Paciolla, ${ }^{35}$ Martina Pagliuca, ${ }^{24}$ Giuseppe Palmieri, ${ }^{36}$ Sara Parola, ${ }^{24}$ Stefano Pepe, ${ }^{37}$ Angelica Petrillo (D) , ${ }^{12,19}$ Francovito Piantedosi, ${ }^{38}$ Luisa Piccin, ${ }^{39}$ Fernanda Picozzi, ${ }^{24}$ Erica Pietroluongo, ${ }^{24}$ Sandro Pignata, ${ }^{9}$ Veronica Prati, ${ }^{40}$ Vittorio Riccio, ${ }^{24}$ Mario Rosanova, ${ }^{12}$ Alice Rossi, ${ }^{29}$ Anna Russo, ${ }^{41}$ Massimiliano Salati, ${ }^{42}$ Giuseppe Santabarbara, ${ }^{26}$ Andrea Sbrana, ${ }^{11}$ Ester Simeone ${ }^{3}$ Antonia Silvestri, ${ }^{12}$ Massimiliano Spada, ${ }^{43}$ Paolo Tarantino, ${ }^{44}$ Paola Taveggia, ${ }^{18}$ Federica Tomei, ${ }^{8}$ Tortora Vincenzo, ${ }^{24,37}$ Dario Trapani, ${ }^{44}$ Claudia Trojanello, ${ }^{3}$ Vito Vanella, ${ }^{3}$ Sabrina Vari, ${ }^{45}$ Jole Ventriglia, ${ }^{46}$ Maria Grazia Vitale, ${ }^{3,32}$ Fabiana Vitiello, ${ }^{38}$ Caterina Vivaldi, ${ }^{11}$ Claudia von Arx, ${ }^{47}$ Francesca Zacchi, ${ }^{48}$ Ilaria Zampiva, ${ }^{48}$ Andrea Zivi, ${ }^{47,49}$ Bruno Daniele, ${ }^{12}$ Paolo Antonio Ascierto (D) , ${ }^{3}$ On behalf of SCITO (Società Campana di ImmunoTerapia Oncologica)

\section{ABSTRACT}

Background The coronavirus disease 2019 (COVID-19) pandemic has overwhelmed the health systems worldwide. Data regarding the impact of COVID-19 on cancer patients (CPs) undergoing or candidate for immune checkpoint inhibitors (ICls) are lacking. We depicted the practice and adaptations in the management of patients with solid tumors eligible or receiving ICls during the COVID-19 pandemic, with a special focus on Campania region.

Methods This survey (25 questions), promoted by the young section of SCITO (Società Campana di ImmunoTerapia Oncologica) Group, was circulated among Italian young oncologists practicing in regions variously affected by the pandemic: high (group 1), medium (group 2) and low (group 3) prevalence of SARS-CoV-2-positive patients. For Campania region, the physician responders were split into those working in cancer centers (CC), university hospitals (UH) and general hospitals (GH). Percentages of agreement, among High $(\mathrm{H})$ versus Medium
(M) and versus Low (L) group for Italy and among CC, UH and $\mathrm{GH}$ for Campania region, were compared by using Fisher's exact tests for dichotomous answers and $\chi^{2}$ test for trends relative to the questions with 3 or more options. Results This is the first Italian study to investigate the COVID-19 impact on cancer immunotherapy, unique in its type and very clear in the results. The COVID-19 pandemic seemed not to affect the standard practice in the prescription and delivery of ICls in Italy. Telemedicine was widely used. There was high consensus to interrupt immunotherapy in SARS-CoV-2-positive patients and to adopt ICls with longer schedule interval. The majority of the responders tended not to delay the start of ICls; there were no changes in supportive treatments, but some of the physicians opted for delaying surgeries (if part of patients' planned treatment approach). The results from responders in Campania did not differ significantly from the national ones.

Conclusion Our study highlights the efforts of Italian oncologists to maintain high standards of care for CPs
Dr Paolo Antonio Ascierto; paolo.ascierto@gmail.com 
treated with ICls, regardless the regional prevalence of COVID-19, suggesting the adoption of similar solutions. Research on patients treated with ICls and experiencing COVID-19 will clarify the safety profile to continue the treatments, thus informing on the most appropriate clinical conducts.

\section{INTRODUCTION}

The world is currently in the midst of the largest medical emergency since the influenza pandemic of 1918, due to the novel respiratory syndrome COVID-19 ('coronavirus disease 2019') pandemic, caused by the coronavirus SARS-CoV-2, with over 3,767,744 diagnosed cases and 259,593 deaths across 210 countries around the world, as of May 8, 2020. ${ }^{1}$ The outbreak of COVID-19, declared as a pandemic by WHO on March $11,2020,{ }^{2}$ has overwhelmed the public health systems worldwide. Originated in China, and then moved to Europe and Italy, the scenario of virus rapid spread has resulted in high number of cases and relative deaths, ${ }^{2}$ and prompted the implementation of public health measures of containment to prevent the disease transmission, protect healthcare workers, and increase healthcare-system capacity, especially intensive care units and COVID-19 dedicated areas. ${ }^{3}$ As widely recognized, the risk and the severity of COVID-19 infection seem to be associated with older age and pre-existing comorbidities, such as diabetes, chronic cardiopulmonary disease and immune depression, ${ }^{4}$ thus cancer patients (CPs) and cancer survivors could represent additional high-risk categories. ${ }^{5}$ Considering the prevalence of cancer worldwide and the current COVID-19 pandemic, there is an urgent need to depict the effects of this new infection on cancer treatments, to ensure protection of one possible vulnerable population of patients. In response to the lack of reliable data on CPs and navigating in a plethora of assumptions, opinions and perspectives that are not evidence based, several international collaborations have been developed, including the Research Collaborative Registry for Hematologic Malignancy (led by the American Society of Hematology), the TERAVOLT group study ("thoracic cancers international COVID-19 collaboration", led by the Italian National Cancer Institute), the UK Coronavirus cancer-monitoring project, the American Association of Clinical Oncology Survey on COVID-19 in Oncology Registry, the web-based CCC19 Registry (the COVID-19 and Cancer Consortium) and the European Society of Medical Oncology ESMOCoCARE registry (online supplemental appendix table 1). ${ }^{6}$ However, to date, the CP populations described in several reports lack extensive descriptions of individuals receiving anticancer immune checkpoint inhibitors (ICIs), ${ }^{7}$ which represent the standard option in several solid tumors such as melanoma and non-melanoma skin tumors, lung cancer, renal carcinoma, urothelial cancers, head and neck carcinoma, and more recently, breast cancers. ${ }^{8}$ Therefore, with the aim to depict the management of CPs with solid tumors undergoing or candidate for ICIs during the COVID-19 pandemic, a survey promoted by the young section of SCITO (Società Campana di
ImmunoTerapia Oncologica), ${ }^{9}$ which includes certified oncologists under 45 years old, was circulated among Italian young oncologists.

\section{METHODS}

The survey was generated by the young section of the cooperative network SCITO and sent by email, from April 10 to May 8, 2020, to Italian young oncologists with recognized experience in anticancer immunotherapy, who were assigned to three group of regions, according to the national COVID-19 epidemiological data of May 8, 2020 (data cutoff): group 1, high $(\mathrm{H})$ prevalence regions with more than 10,000 positive patients; group 2 , medium $(\mathrm{M})$ prevalence regions with positive patients less than 10,000 and more than 4000; group 3, low (L) prevalence regions with less than 4000 positive patients (figure 1). The survey consisted of 25 questions, which were organized in three sections. The first section (from question number 1 to question number 8) assessed the routine triaging-screening procedures for SARS-CoV-2 in CPs undergoing or candidate for ICIs, the COVID-19 containment measures adopted and the positivity for COVID-19 in CPs while on immunotherapies. At the time of data cut-off, according to the indications of the Italian National Institute of Health, triage of oncological patients included vital signs monitoring before entering the oncologic clinic (body temperature, $\mathrm{SpO}_{2}$, respiratory rate) and questioning patients on the presence of suspicious symptoms during the 15 days before the visit and possible contacts with subjects affected by COVID-19 or coming from high-risk areas. In case of suspicious symptoms or possible contacts, the triage procedure was followed by preventive isolation and diagnostic work-up according to the regional specific indications. The second section (from question number 9 to question number 20) assessed the treatment modality adaptations for medical and surgical treatments provided to CPs undergoing or candidate for ICIs during the COVID-19 pandemic, as well as the adaptations of supportive therapies. The third and last section (from question number 21 to question number 25) assessed the physicians' characteristics such as age, professional position, affiliation, geographical distribution and field of interest. A complete original version of the survey is provided in online supplemental appendix. The answers were collected and reviewed by two reference members of SCITO young section (MO and MC). The survey responses were analyzed blinded for the submitting author's identity. The percentage of consensus among the $\mathrm{H}, \mathrm{M}$ and $\mathrm{L}$ COVID-19 prevalence regions (CPR) and among the cancer centers (CC), university hospitals (UH) and general hospitals $(\mathrm{GH})$ of Campania Region were compared by using Fisher's exact tests for dichotomous answers and $\chi^{2} \log$ test for the questions with three or more options. All tests were two sided. Significance was set at $\mathrm{p}$ value $<0.05$ (only the $\mathrm{p}$ value for significant results has been shown). The data were analyzed using GraphPad Prism V.8.3.0 (GraphPad Software, San Diego, CA, USA). The epidemiology data about the COVID-19 prevalence and mortality were extracted from the Italian Health Minister website (http://www.salute. 


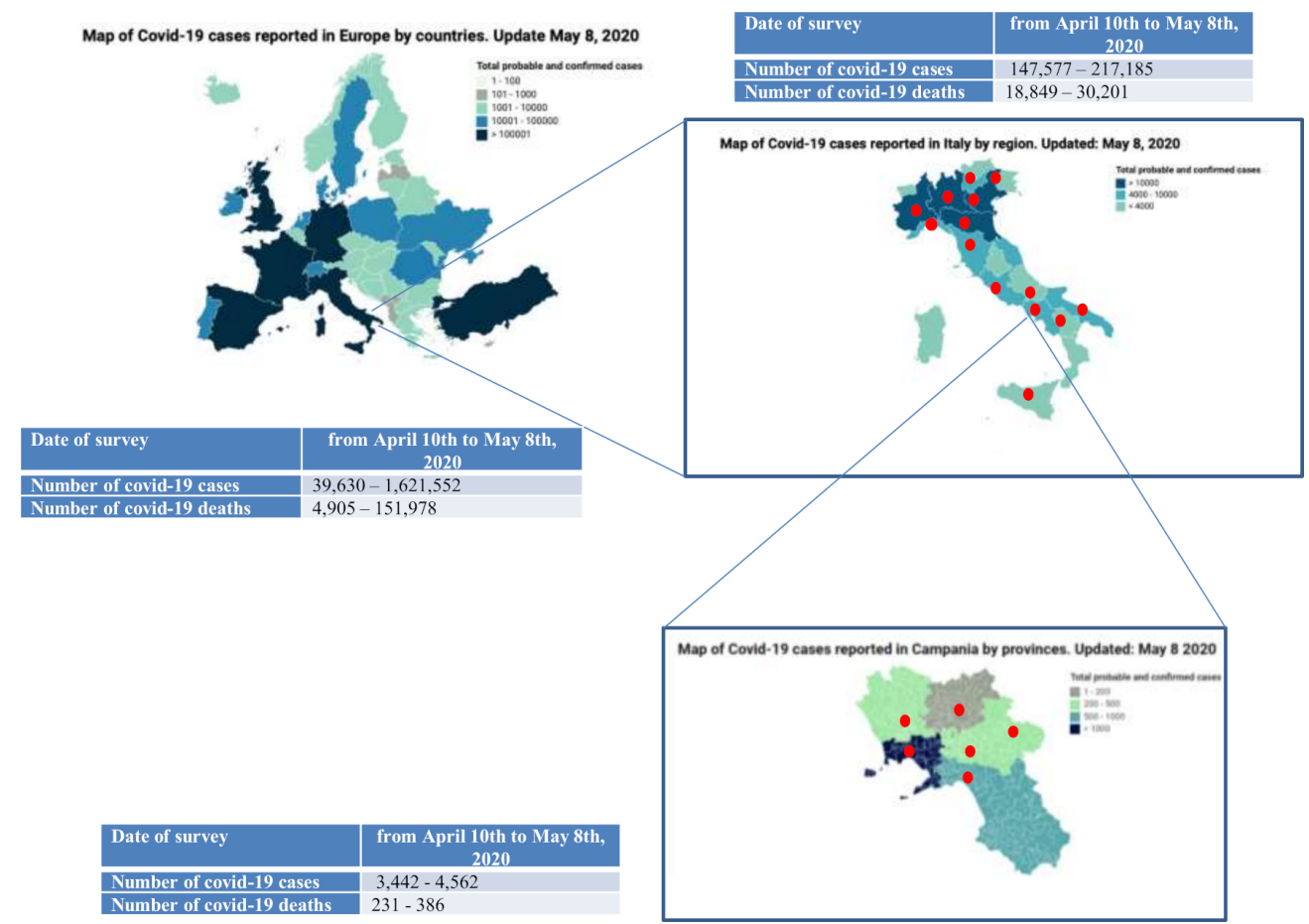

Figure 1 Epidemiology of COVID-19. Epidemic graphic maps of Europe (A), Italy (B) and Campania (C) at the end time of circulation of the survey among young Italian oncologists. The maps report the prevalence of COVID-19-positive patients corresponding to the last day of the survey dates interval (May 8). The tables report the survey dates, the prevalence of COVID-19-positive patients and COVID-19-related deaths at the time of the survey. The red dots mark the geographic areas of the physician responders.

govit/portale/nuovocoronavirus/); the data-wrapper software (https://www.datawrapper.de) was used to create the epidemic graph maps.

Table 1 Characteristics of physicians who responded to the survey (survey section 3 )

\begin{tabular}{|c|c|c|}
\hline & $\begin{array}{l}\text { Total number } \\
\text { and } \% \text { Italy }\end{array}$ & $\begin{array}{l}\text { Total number and } \\
\% \text { Campania }\end{array}$ \\
\hline & 75 responders & 38 responders \\
\hline \multicolumn{3}{|l|}{ Professional position } \\
\hline Specialists & $49(65.3 \%)$ & $26(68.4 \%)$ \\
\hline Trainees & $26(34.7 \%)$ & $12(31.6 \%)$ \\
\hline \multicolumn{3}{|l|}{ Age } \\
\hline$<35$ years old & $43(57.3 \%)$ & $20(52.6 \%)$ \\
\hline$>35$ years old & $32(42.7 \%)$ & $18(47.4 \%)$ \\
\hline \multicolumn{3}{|l|}{ Affiliation } \\
\hline Cancer center & $23(30.7 \%)$ & $10(26.4 \%)$ \\
\hline University hospital & $24(32 \%)$ & $12(31.5 \%)$ \\
\hline General hospital & $28(37.3 \%)$ & $16(42.1 \%)$ \\
\hline \multicolumn{3}{|l|}{ Field of interest } \\
\hline Thoracic cancers & $27(36 \%)$ & 15 (39.4\%) \\
\hline Urogenital cancers & 17 (22.7\%) & $8(21 \%)$ \\
\hline Melanoma & $13(17.3 \%)$ & $8(21 \%)$ \\
\hline Others & $18(24 \%)$ & $7(18.3 \%)$ \\
\hline
\end{tabular}

\section{RESULTS}

Seventy-five young oncologists, daily involved in the management of CPs treated with ICIs, responded to the survey, with a $100 \%$ survey completion rate. Seventeen physicians belonged to H CPR, fifty-one and seven physicians to, respectively, M and L CPR. All the participants were medical oncologists, with the exception of a radiation oncologist. For the Campania Region analysis, 38 oncologists were included, divided into 10 for CC, 12 for $\mathrm{UH}$ and 16 for GH. To simplify consultation and interpretation of results, tables 1 and 2 show physicians' characteristics and geographical collocation (third survey's section); tables 3 and 4 show answers to multiple-choice questions of first and second sections; tables 5 and 6 show answers to multiple-choice questions of first and second sections relatively to Campania region's oncologists. Figure 1 reports the epidemic graph maps of the COVID-19 pandemic at the time of the last collection of survey responses (May 8) for Europe, Italy and Campania Region, respectively.

\section{Italian experience: differences and similarities among high (H), medium (M) and low (L) COVID-19 prevalence regions (CPR)}

CPs were preferentially triaged for COVID-19-related symptoms on the day before the hospital appointment by telephonic consultation and on the day of clinic appointment through physical examinations in dedicated areas in $\mathrm{H}$ and $\mathrm{M}$ CPR $(\mathrm{H}=82.4 \%$; $\mathrm{M}=58.8 \%)$, while in the $\mathrm{L}$ 
Table 2 Geographical distribution and affiliations of physicians who responded to the survey (survey section 3)

\begin{tabular}{|c|c|c|c|}
\hline Name of institution & City & Region & Type \\
\hline A.O. Moscati & Avellino & Campania & $\mathrm{GH}$ \\
\hline A.O. Dei Colli Ospedale Monaldi & Naples & Campania & $\mathrm{GH}$ \\
\hline A.O. Ordine Mauriziano & Torino & Piemonte & $\mathrm{GH}$ \\
\hline A.O.U. degli studi della Campania "Luigi Vanvitelli" & Naples & Campania & $\mathrm{UH}$ \\
\hline A.O.U. degli studi di Napoli Federico II & Naples & Campania & UH \\
\hline A.O.U. di Modena & Modena & Emilia Romagna & UH \\
\hline A.O.U. di Pisa & Pisa & Toscana & UH \\
\hline A.O.U. San Giovanni di Dio Ruggi d'Aragona & Salerno & Campania & $\mathrm{UH}$ \\
\hline A.O.U.I. di Verona & Verona & Veneto & UH \\
\hline A.S.L. Caserta Presidio San Felice a Cancello & Caserta & Campania & $\mathrm{GH}$ \\
\hline A.S.L. Caserta Presidio Sessa Aurunca Ospedale San Rocco & Caserta & Campania & $\mathrm{GH}$ \\
\hline A.S.L. CN2 Alba-Bra & Verduno & Piemonte & $\mathrm{GH}$ \\
\hline A.S.L. Napoli 1 Centro Ospedale del Mare & Naples & Campania & $\mathrm{GH}$ \\
\hline Azienda Sanitaria Universitaria Integrata del Friuli Centrale & Udine & Friuli Venezia Giulia & UH \\
\hline Fondazione IRCCS Istituto Nazionale dei Tumori & Milan & Lombardia & $\mathrm{CC}$ \\
\hline Fondazione Istituto G. Giglio & Cefalù & Sicilia & $\mathrm{GH}$ \\
\hline Gemelli Molise s.p.a & Campobasso & Molise & $\mathrm{CC}$ \\
\hline IRCCS “Giovanni Paolo II” & Bari & Puglia & $\mathrm{CC}$ \\
\hline IRCCS CROB & Rionero in Vulture & Basilicata & $\mathrm{CC}$ \\
\hline Istituto Europeo di Oncologia-IEO & Milan & Lombardia & $\mathrm{CC}$ \\
\hline Istituto Nazionale dei Tumori "Regina Elena"-IRCCS & Rome & Lazio & $\mathrm{CC}$ \\
\hline Istituto Nazionale dei Tumori Fondazione G. Pascale-IRCCS & Naples & Campania & $\mathrm{CC}$ \\
\hline Istituto Oncologico del Veneto IRCCS-IOV & Padua & Veneto & $\mathrm{CC}$ \\
\hline $\begin{array}{l}\text { Istituto Scientifico Romagnolo per lo Studio e la Cura dei Tumori (IRST) } \\
\text { IRCCS }\end{array}$ & Meldola & Emilia Romagna & $\mathrm{CC}$ \\
\hline Ospedale Della Murgia "F. Perinei" & Altamura & Puglia & $\mathrm{GH}$ \\
\hline Ospedale Fatabenefratelli & Benevento & Campania & $\mathrm{GH}$ \\
\hline Ospedale S. Ottone Frangipane & Ariano Irpino & Campania & $\mathrm{GH}$ \\
\hline Ospedale Sant'Anna e San Sebastiano & Caserta & Campania & $\mathrm{GH}$ \\
\hline Ospedale Santa Chiara & Trento & Trentino Alto Adige & $\mathrm{GH}$ \\
\hline Ospedale SS. Antonio e Biagio e Cesare Arrigo & Alessandria & Piemonte & $\mathrm{GH}$ \\
\hline Ospedale Veneziale & Isernia & Molise & $\mathrm{GH}$ \\
\hline Ospedale Villa Scassi, A.S.L. 3 Genova & Genoa & Liguria & $\mathrm{GH}$ \\
\hline Ospedali Riuniti Villa Sofia Cervello & Palermo & Sicilia & $\mathrm{GH}$ \\
\hline Università degli studi di Verona, sede Borgo Roma & Verona & Veneto & $\mathrm{UH}$ \\
\hline
\end{tabular}

$\mathrm{CC}$, cancer center; GH, general hospital; UH, university hospital.

CPR, $57.1 \%$ of responders clinically assessed CPs directly in-person on the day of clinic appointment without any previous telephonic triage $(\mathrm{p}=0.03)$. Despite these differences, for patients suspected of COVID-19, there was high consensus on precautionary ICI interruptions and resuming the treatment after a SARS-CoV-2 negative result; only $4 \%$ of the responders reported to consider continuing ongoing ICIs in possibly symptomatic patients, thus avoiding treatment delays. Moreover, for clinically suspected cases, $11.8 \%$ of $\mathrm{H}, 35.3 \%$ of $\mathrm{M}$ and
28.6\% of L CPR responders did not perform any additional diagnostic work-up, whereas for the remaining physicians, there was no consensus on the best diagnostic algorithm to follow. The preferred management option was immediate ICI interruption, then perform thorax CT scan even in the absence of severe respiratory symptoms and order blood test including complete blood count $(\mathrm{CBC})$, lactate dehydrogenase, high-sensitivity $\mathrm{C}$ reactive protein, interleukin- 6 and D-dimer $(\mathrm{H}=11.8 \%, \mathrm{M}=15.7 \%$, $\mathrm{L}=14.3 \%)$. Due to the inclusion of oncologists working 
Table 3 Answers to multiple choice questions of survey section 1

\begin{tabular}{|c|c|c|c|c|c|}
\hline \multirow[b]{2}{*}{ Questions } & \multirow[b]{2}{*}{ Multiple-choice responses } & \multirow{2}{*}{$\begin{array}{l}\text { All, } n \text { (\%) } \\
\mathrm{N}=75\end{array}$} & \multirow{2}{*}{$\begin{array}{l}\text { H CPR, n (\%) } \\
\mathrm{N}=17\end{array}$} & \multirow{2}{*}{$\begin{array}{l}\text { M CPR, n (\%) } \\
\mathrm{N}=51\end{array}$} & \multirow{2}{*}{$\begin{array}{l}\text { L CPR, n (\%) } \\
\mathrm{N}=7\end{array}$} \\
\hline & & & & & \\
\hline \multirow{3}{*}{$\begin{array}{l}\text { 1. How do you triage your (CP-ICI) patients for } \\
\text { SARS-CoV-2? }\end{array}$} & $\square$ By telephone the day before the appointment & $13(17.3)$ & $1(5.9)$ & $12(23.5)$ & $0(0)$ \\
\hline & $\begin{array}{l}\square \text { Outside the hospital the same day of the clinic } \\
\text { appointment }\end{array}$ & $15(20)$ & $2(11.8)$ & $9(17.6)$ & $4(57.1)$ \\
\hline & $\begin{array}{l}\square \text { By telephone the day before the appointment and } \\
\text { outside the clinic the day of the appointment }\end{array}$ & $47(62.7)$ & $14(82.4)$ & $30(58.8)$ & $3(42.9)$ \\
\hline \multirow[t]{4}{*}{$\begin{array}{l}\text { 2. Who among } \mathrm{CP}-\mathrm{ICI} \text { patients do you } \\
\text { preferentially use telemedicine? }\end{array}$} & $\begin{array}{l}\square \text { Patients in follow-up after finishing } \mathrm{ICl} \text { adjuvant } \\
\text { treatment }\end{array}$ & $7(9.3)$ & $2(11.8)$ & $5(9.8)$ & $0(0)$ \\
\hline & $\begin{array}{l}\square \text { Patients in follow-up who achieve complete } \\
\text { response }\end{array}$ & $3(4)$ & $2(11.8)$ & $1(2)$ & $0(0)$ \\
\hline & $\square$ Both & $57(76)$ & $11(64.7)$ & $40(78.4)$ & $6(85.7)$ \\
\hline & $\square$ None of the above, I am not using telemedicine & $8(10.7)$ & $2(11.8)$ & $5(9.8)$ & $1(14.3)$ \\
\hline \multirow{4}{*}{$\begin{array}{l}\text { 3. How do you manage the new patients with } \\
\text { cancer who need to start ICls for metastatic } \\
\text { disease? }\end{array}$} & $\square$ Delay ICI start for COVID-19 in all patients & $0(0)$ & $0(0)$ & $0(0)$ & $0(0)$ \\
\hline & $\square$ Triage screening for COVID-19 risk factors & 69 (92) & $16(94.1)$ & $46(90.2)$ & $7(100)$ \\
\hline & $\square$ Both & $2(2.7)$ & $0(0)$ & $2(3.9)$ & $0(0)$ \\
\hline & $\square$ None of the above & $4(5.3)$ & $1(5.9)$ & $3(5.9)$ & $0(0)$ \\
\hline \multirow{4}{*}{$\begin{array}{l}\text { 4. How do you manage the new patients with } \\
\text { cancer who need to start ICls for adjuvant } \\
\text { purpose? }\end{array}$} & $\square$ Delay ICI start for COVID-19 in all patients & $2(2.7)$ & $1(5.9)$ & $1(2)$ & $0(0)$ \\
\hline & $\square$ Triage screening for COVID-19 risk factors & $60(0)$ & $15(88.2)$ & $41(80.4)$ & $4(57.1)$ \\
\hline & $\square$ Both & $7(9.3)$ & $0(0)$ & $5(9.8)$ & $2(28.6)$ \\
\hline & $\square$ None of the above & $6(8)$ & $1(5)$. & $4(7.8)$ & $1(14.3)$ \\
\hline \multirow{2}{*}{$\begin{array}{l}\text { 5. Do you have any CP-ICI who tested positive for } \\
\text { SARS-CoV-2? }\end{array}$} & $\square$ Yes & $21(28)$ & $5(29.4)$ & $16(31.4)$ & $0(0)$ \\
\hline & $\square$ No & $54(72)$ & $12(70.6)$ & $35(68.6)$ & $7(100)$ \\
\hline \multirow[t]{4}{*}{ 6. If yes, how many? } & $\square<10$ & $24(96)$ & $6(100)$ & $18(94.7)$ & $0(0)$ \\
\hline & $\square$ 10-20 & $1(4)$ & $0(0)$ & $1(5.3)$ & $0(0)$ \\
\hline & $\square 20-50$ & $0(0)$ & $0(0)$ & $0(0)$ & $0(0)$ \\
\hline & $\square 50-100$ & $0(0)$ & $0(0)$ & $0(0)$ & $0(0)$ \\
\hline \multirow{5}{*}{$\begin{array}{l}\text { 7. If yes, the most frequent CP-ICI SARS-CoV-2 } \\
\text { positive are affected by? }\end{array}$} & $\square$ Urogenital cancers & $5(20)$ & $2(33.3)$ & $3(16)$ & $0(0)$ \\
\hline & $\square$ Thoracic cancers & $14(56)$ & $2(33.3)$ & $12(63)$ & $0(0)$ \\
\hline & $\square$ Melanoma & $5(20)$ & $1(16.6)$ & $4(21)$ & $0(0)$ \\
\hline & $\square$ Head and neck cancers & $0(0)$ & $0(0)$ & $0(0)$ & $0(0)$ \\
\hline & $\square$ Other & $1(4)$ & $1(16.6)$ & $0(0)$ & $0(0)$ \\
\hline \multirow{11}{*}{$\begin{array}{l}\text { 8. How do you manage CP-ICI showing } \\
\text { suspicious symptoms for COVID-19? (more than } 1 \\
\text { option allowed) }\end{array}$} & $\begin{array}{l}\text { 1. Order the SARS-CoV-2 test and continue with the } \\
\text { ICls avoiding delays }\end{array}$ & $3(4)$ & $1(5.9)$ & $2(3.9)$ & $0(0)$ \\
\hline & 2. Suspend the ICls while waiting for the test results & $22(29.3)$ & $2(11.8)$ & $18(35.3)$ & $2(28.6)$ \\
\hline & $\begin{array}{l}\text { 3. Ask for Rx thorax even in the absence of severe } \\
\text { respiratory symptoms }\end{array}$ & $3(4)$ & $1(5.9)$ & $2(3.9)$ & $0(0)$ \\
\hline & $\begin{array}{l}\text { 4. Ask for thorax CT scan even in the absence of } \\
\text { severe respiratory symptoms }\end{array}$ & $4(5.2)$ & $1(5.9)$ & $2(3.9)$ & $1(14.3)$ \\
\hline & $\begin{array}{l}\text { 5. Ask for blood test including: CBC, lactate } \\
\text { dehydrogenase, high-sensitivity C reactive protein, } \\
\text { interleukin-6, D-dimer }\end{array}$ & $1(1.3)$ & $1(5.9)$ & $0(0)$ & $0(0)$ \\
\hline & 6. $2+5$ & $7(9.3)$ & $2(11.8)$ & $3(5.9)$ & $2(28.6)$ \\
\hline & 7. $2+3$ & $7(9.3)$ & $1(5.9)$ & $6(11.8)$ & $0(0)$ \\
\hline & 8. $2+3+5$ & 10 (13.3) & $5(29.4)$ & $5(9.8)$ & $0(0)$ \\
\hline & 9. $2+3+4$ & $1(1.3)$ & $0(0)$ & $1(2)$ & $0(0)$ \\
\hline & 10. $2+4$ & 7 (9.3) & $1(5.9)$ & $5(9.8)$ & $1(14.3)$ \\
\hline & 11. $2+4+5$ & $11(14.7)$ & $2(11.8)$ & $8(15.7)$ & $1(14.3)$ \\
\hline
\end{tabular}

H CPR: high (H) prevalence regions with more than 10,000 positive patients, M CPR: medium (M) prevalence regions with positive patients less than 10,000 and more than 4000, L CPR: low (L) prevalence regions with less than 4000 positive patients.

$\mathrm{CBC}$, complete blood count; CP, cancer patient; CP-ICl, cancer patients undergoing or candidate for immune checkpoint inhibitor; ICl, immune checkpoint inhibitor; $\mathrm{N}$, number.

in different contexts such as $\mathrm{CC}, \mathrm{UH}$ and $\mathrm{GH}$, including the ones hosting COVID-19 units, CPs treated with ICIs were predominantly seen in non "COVID-19 free" institutions $(\mathrm{H}=64.7 \%, \mathrm{M}=58.8 \%, \mathrm{~L}=71.4 \%)$. As expected, telemedicine was largely implemented, both for patients in follow-up after completing ICI adjuvant treatment or achieving ICI complete response; only $11.8 \%, 9.8 \%$ and $14.3 \%$ of responders in $\mathrm{H}, \mathrm{M}$ and $\mathrm{L}$ CPR used a different approach. High percentage of responders $(\mathrm{H}=88.2 \%$, $\mathrm{M}=80.4 \%, \mathrm{~L}=57.1 \%$ ) stated to screen all new CPs for 
Table 4 Answers to multiple choice questions of survey section 2

\begin{tabular}{|c|c|c|c|c|c|}
\hline & & All, $n$ (\%) & H CPR, n (\%) & M CPR, n (\%) & L CPR, n (\%) \\
\hline Questions & Multiple-choice responses & $\mathrm{N}=75$ & $\mathrm{~N}=17$ & $\mathrm{~N}=51$ & $\mathrm{~N}=7$ \\
\hline \multirow[t]{3}{*}{$\begin{array}{l}\text { 1. Do you have any preference in the schedule of } \mathrm{ICl} \\
\text { choice for the treatment of CPs? }\end{array}$} & $\begin{array}{l}\square \text { Yes, I prefer the schedule with the shorter } \\
\text { interval }\end{array}$ & $31(41.3)$ & $9(52.9)$ & $21(41.2)$ & $1(14.3)$ \\
\hline & $\begin{array}{l}\square \text { Yes, I prefer the schedule with the longer } \\
\text { interval }\end{array}$ & $39(52)$ & $7(41.2)$ & $26(51)$ & $6(85.7)$ \\
\hline & $\begin{array}{l}\square \text { No, the schedule interval is not a criteria } \\
\text { for ICl choice in my clinical practice }\end{array}$ & $5(6.7)$ & $1(5.9)$ & $4(7.8)$ & $0(0)$ \\
\hline \multirow{2}{*}{$\begin{array}{l}\text { 2. Do you have currently (during COVID-19 pandemic) } \\
\text { any preference in the schedule of ICls for the treatment } \\
\text { of CPs? }\end{array}$} & $\begin{array}{l}\square \text { Yes, I prefer the schedule with the longer } \\
\text { interval }\end{array}$ & $58(77.3)$ & $13(76.5)$ & $38(74.5)$ & $7(100)$ \\
\hline & $\begin{array}{l}\square \text { No, the schedule interval is not a criteria } \\
\text { for ICl choice in my current clinical practice }\end{array}$ & $17(22.7)$ & $2(23.5)$ & $13(25.5)$ & $0(0)$ \\
\hline $\begin{array}{l}\text { 3. Have you modified the dose of steroids you give in } \\
\text { case of ICl adverse events? }\end{array}$ & $\square$ Yes, I have reduced the dose & $3(4)$ & $1(1.9)$ & $1(2)$ & $1(14.3)$ \\
\hline $\begin{array}{l}\text { 4. Has the COVID- } 19 \text { pandemic changed your treatment } \\
\text { choice for CP-ICI in case of alternative treatments like } \\
\text { chemotherapy, where applicable, as for clinical practice } \\
\text { guidelines? }\end{array}$ & $\square$ No & 69 (92) & $16(94.1)$ & $46(90.2)$ & $7(100)$ \\
\hline \multirow{2}{*}{$\begin{array}{l}\text { 5. Has the COVID-19 pandemic changed your treatment } \\
\text { choice for CP-ICI in case of alternative treatments } \\
\text { like targeted therapy, where applicable, as for clinical } \\
\text { practice guidelines? }\end{array}$} & $\square$ Yes & $9(12)$ & $2(11.8)$ & $6(11.8)$ & $1(14.3)$ \\
\hline & $\square$ No & $66(88)$ & $15(88.2)$ & $45(88.2)$ & $6(85.7)$ \\
\hline \multirow{2}{*}{$\begin{array}{l}\text { 6. Are the CP-ICl preferentially seen in COVID-19 clear } \\
\text { institutions? }\end{array}$} & $\square$ Yes & $29(38.7)$ & $6(35.3)$ & $21(41.2)$ & $2(28.6)$ \\
\hline & $\square$ No & $46(61.3)$ & $11(64.7)$ & $30(58.8)$ & $5(71.4)$ \\
\hline \multirow{2}{*}{$\begin{array}{l}\text { 7. Do you use G-CSF in case of CP-ICls with no febrile } \\
\text { neutropenia (when used } \pm \text { chemotherapy)? }\end{array}$} & $\square$ Yes & $12(16)$ & $1(5.9)$ & $11(21.6)$ & $0(0)$ \\
\hline & $\square$ No & $63(84)$ & $16(94.1)$ & $40(78.4)$ & 7 (100) \\
\hline $\begin{array}{l}\text { 8. Has this decision been changed by the COVID- } 19 \\
\text { pandemic? }\end{array}$ & $\square$ Yes & $6(8)$ & $2(11.8)$ & $4(7.8)$ & $0(0)$ \\
\hline $\begin{array}{l}\text { 11. Do you prefer to delay ICl start in lung cancer } \\
\text { patients because of potential lung toxicity considering } \\
\text { the high lung tropism of SARS-CoV-2 virus and its risk } \\
\text { of ARDS? }\end{array}$ & $\square$ No & $67(89.3)$ & $14(82.4)$ & 47 (92.2) & $6(85.7)$ \\
\hline \multirow{2}{*}{$\begin{array}{l}\text { 12. In your institution, has surgery for CP been delayed } \\
\text { because of the COVID-19 pandemic? }\end{array}$} & $\square$ Yes & $35(46.7)$ & $9(52.9)$ & $24(47.1)$ & $2(28.6)$ \\
\hline & $\square$ No & $40(53.3)$ & $8(47.1)$ & 27 (52.9) & $5(71.4)$ \\
\hline
\end{tabular}

H CPR: high (H) prevalence regions with more than 10,000 positive patients, M CPR: medium (M) prevalence regions with positive patients less than 10,000 and more than 4000 , $L$ CPR: low (L) prevalence regions with less than 4000 positive patients.

ARDS, acute respiratory distress syndrome; $\mathrm{CP}$, cancer patient; $\mathrm{CP}-\mathrm{ICl}$, cancer patients undergoing or candidate for immune checkpoint inhibitor; ICI, immune checkpoint inhibitor; $\mathrm{N}$, number.

SARS-CoV-2 before starting adjuvant ICIs, while only $5.9 \%, 11.8 \%$ and $28.6 \%$ from H, M and L CPR delayed ICI start independently of the COVID-19 screening. Intriguingly, for metastatic CPs, there was nearly unanimous consent on the use of screening test for COVID-19, avoiding ICI start delays ( $\mathrm{H}=94.1 \%, \mathrm{M}=90.2 \%, \mathrm{~L}=100 \%)$. None of the L CPR physicians had any of the CPs treated with ICIs positive for SARS-CoV-2, while $29.4 \%$ and $31.4 \%$ of the $\mathrm{H}$ and $\mathrm{M}$ CPR had less than 10 positive patients. The majority of these CPs were affected by thoracic cancers, followed by melanoma, and urogenital and breast cancers. Some differences emerged about the preference of ICI schedule interval. Routinely, 52.9\%, $41.25 \%$ and $14.3 \%$ of H, M and L CPR physicians would not use the schedule interval as a criterion of choice for ICI treatment; however, an ICI with a longer schedule interval was preferable for $41.2 \%, 51 \%$ and $85.7 \%$ of $\mathrm{H}, \mathrm{M}$ and L CPR responders. Despite these differences, there was high consensus on the preference of longer ICI schedule interval during the COVID-19 pandemic ( $\mathrm{H}=76.5 \%$, $\mathrm{M}=74.5 \%, \mathrm{~L}=100 \%$ ), with none of the participants opting for a shorter ICI schedule interval. There was also a large consensus about not modifying the recommended steroid dose in case of immune-related adverse events (ir-AEs) $(\mathrm{H}=94.1 \%, \mathrm{M}=98 \%, \mathrm{~L}=85.7 \%)$. Moreover, the majority of physicians did not change the ICI indication in favor 
Table 5 Answers to multiple choice questions of survey section 1 for Campania region

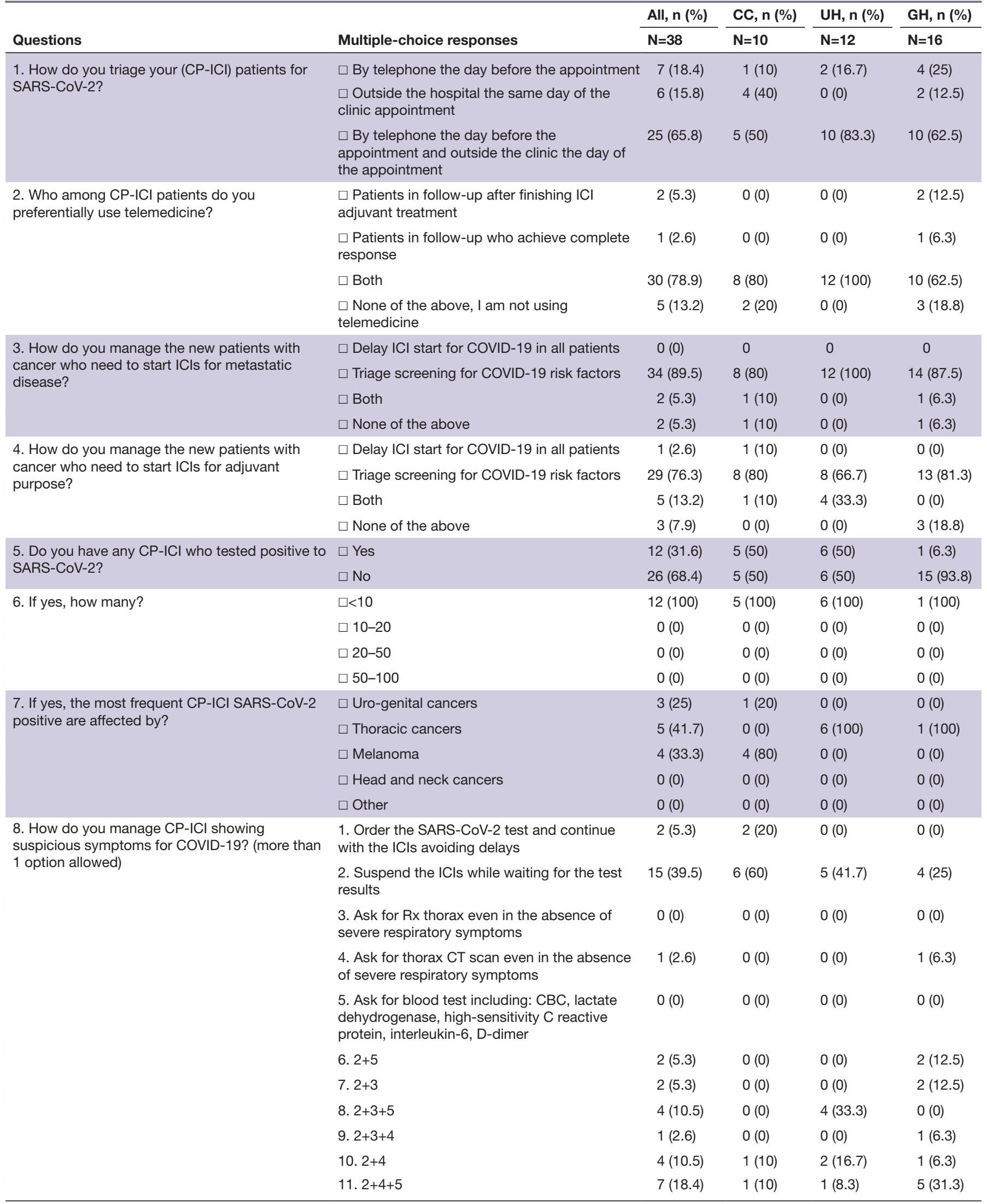

CBC, complete blood count; CC, cancer center; CP, cancer patient; $\mathrm{CP}-\mathrm{ICI}$, cancer patients undergoing or candidate for immune checkpoint inhibitor; GH, general hospital; ICI, immune checkpoint inhibitor; N, number; UH, university hospital. 
Table 6 Answers to multiple choice questions of survey section 2 for Campania region

\begin{tabular}{|c|c|c|c|c|c|}
\hline & & All, $n(\%)$ & CC, n (\%) & UH, n (\%) & GH, n (\%) \\
\hline Questions & Multiple-choice responses & $\mathrm{N}=38$ & $\mathrm{~N}=10$ & $\mathrm{~N}=12$ & $\mathrm{~N}=16$ \\
\hline \multirow[t]{3}{*}{$\begin{array}{l}\text { 1. Do you have any preference in the schedule } \\
\text { of ICl choice for the treatment of CPs? }\end{array}$} & $\begin{array}{l}\square \text { Yes, I prefer the schedule with the } \\
\text { shorter interval }\end{array}$ & $4(10.5)$ & $0(0)$ & $3(25)$ & $1(6.3)$ \\
\hline & $\begin{array}{l}\square \text { Yes, I prefer the schedule with the } \\
\text { longer interval }\end{array}$ & $18(47.4)$ & $6(60)$ & $5(41.7)$ & $7(43.8)$ \\
\hline & $\begin{array}{l}\square \text { No, the schedule interval is not a criteria } \\
\text { for ICl choice in my clinical practice }\end{array}$ & $16(42.1)$ & $4(40)$ & $4(33.3)$ & $8(50)$ \\
\hline \multirow{2}{*}{$\begin{array}{l}\text { 2. Do you have currently (during COVID-19 } \\
\text { pandemic) any preference in the schedule of } \\
\text { ICls for the treatment of CPs? }\end{array}$} & $\begin{array}{l}\square \text { Yes, I prefer the schedule with the } \\
\text { longer interval }\end{array}$ & $28(73.7)$ & $7(70)$ & $8(66.7)$ & $13(81.3)$ \\
\hline & $\begin{array}{l}\square \text { No, the schedule interval is not a } \\
\text { criteria for } \mathrm{ICl} \text { choice in my current clinical } \\
\text { practice }\end{array}$ & $10(26.3)$ & $3(30)$ & $4(33.3)$ & $3(18.8)$ \\
\hline \multirow{2}{*}{$\begin{array}{l}\text { 4. Has the COVID- } 19 \text { pandemic changed } \\
\text { your treatment choice for } \mathrm{CP}-\mathrm{ICI} \text { in case of } \\
\text { alternative treatments like chemotherapy }\end{array}$} & $\square$ Yes & $4(10.5)$ & $0(0)$ & $2(16.7)$ & $2(12.5)$ \\
\hline & $\square$ No & 34 (89.5) & $10(100)$ & $10(83.3)$ & $14(87.5)$ \\
\hline
\end{tabular}
guidelines?

\begin{tabular}{|c|c|c|c|c|c|}
\hline \multirow{2}{*}{$\begin{array}{l}\text { 5. Has the COVID- } 19 \text { pandemic changed } \\
\text { your treatment choice for } \mathrm{CP}-\mathrm{ICI} \text { in case of } \\
\text { alternative treatments like targeted therapy, } \\
\text { where applicable, as for clinical practice } \\
\text { guidelines? }\end{array}$} & $\square$ Yes & $6(15.8)$ & $2(20)$ & 4 (33.3) & $0(0)$ \\
\hline & $\square$ No & 32 (84.2) & $8(80)$ & $8(66.7)$ & $16(100)$ \\
\hline \multirow{2}{*}{$\begin{array}{l}\text { 6. Are the } \mathrm{CP}-\mathrm{ICI} \text { preferentially seen in } \\
\text { COVID-19 clear institutions? }\end{array}$} & $\square$ Yes & $14(36.8)$ & $2(20)$ & 7 (58.3) & 5 (31.3) \\
\hline & $\square$ No & $24(63.2)$ & $8(80)$ & $5(41.7)$ & $11(68.8)$ \\
\hline \multirow{2}{*}{$\begin{array}{l}\text { 8. Has this decision been changed by the } \\
\text { COVID-19 pandemic? }\end{array}$} & $\square$ Yes & 4 (10.5) & $1(10)$ & $1(8.3)$ & 2 (12.5) \\
\hline & $\square$ No & 34 (89.5) & $9(90)$ & $11(91.7)$ & $14(87.5)$ \\
\hline \multirow{2}{*}{$\begin{array}{l}\text { 9. Have the CP-ICI been managed in expert } \\
\text { centers for immunotherapy? }\end{array}$} & $\square$ Yes & $26(68.4)$ & $8(80)$ & 10 (83.3) & $8(50)$ \\
\hline & $\square$ No & 12 (31.6) & $2(20)$ & $2(16.7)$ & $8(50)$ \\
\hline $\begin{array}{l}\text { 11. Do you prefer to delay ICI start in lung } \\
\text { cancer patients because of potential lung } \\
\text { toxicity considering the high lung tropism of } \\
\text { SARS-CoV-2 virus and its risk of ARDS? }\end{array}$ & $\square$ No & $36(94.7)$ & $10(100)$ & 10 (83.3) & $16(100)$ \\
\hline \multirow{2}{*}{$\begin{array}{l}\text { 12. In your institution, has surgery for CP been } \\
\text { delayed because of the COVID-19 pandemic? }\end{array}$} & $\square$ Yes & $16(42.1)$ & $1(10)$ & $9(75)$ & $6(37.5)$ \\
\hline & $\square$ No & 22 (57.9) & $9(90)$ & $3(25)$ & $10(62.5)$ \\
\hline
\end{tabular}

ARDS, acute respiratory distress syndrome; CC, cancer center; $\mathrm{CP}$, cancer patient; $\mathrm{CP}-\mathrm{ICI}$, cancer patients undergoing or candidate for immune checkpoint inhibitor; G-CSF, granulocyte colony stimulating factor; GH, general hospital; ICl, immune checkpoint inhibitor; N, number; UH, university hospital.

of alternative treatments such as chemotherapy when applicable $(\mathrm{H}=94.1 \%, \mathrm{M}=90.2 \%, \mathrm{~L}=100 \%)$, or targeted therapy $(\mathrm{H}=88.2 \%, \mathrm{M}=88.2 \%, \mathrm{~L}=85.7 \%)$, relatively to solid tumors with actionable target such as renal cancer, hepatocarcinoma and melanoma, where targeted therapy may be used as an alternative to ICI choice regardless of the COVID-19 pandemic, as for clinical practice guidelines. In terms of supportive treatments, there was a large agreement in using the G-CSF only in cases of febrile neutropenia during the COVID-19 pandemic ( $\mathrm{H}=88.2 \%$, $\mathrm{M}=92.2 \%, \mathrm{~L}=100 \%$ ), as well as indicated during the standard clinical practice, for both clinical situation of immunotherapy alone or immunotherapy plus chemotherapy. CPs treated with ICIs were looked after in centers with 
immunotherapy expertise in most cases $(\mathrm{H}=88.2 \%$, $\mathrm{M}=66.7 \%, \mathrm{~L}=51.1 \%$ ), and this strategy was not affected by the COVID-19 pandemic ( $\mathrm{H}=100 \%, \mathrm{M}=98 \%, \mathrm{~L}=100 \%)$. Furthermore, the majority of the physicians did not delay ICI start in lung CPs, although considering the potential lung toxicity related to these agents and despite the high lung tropism of SARS-CoV-2 virus and its risk of acute respiratory distress syndrome (ARDS). On the other hand, delay in surgical treatment was reported by $52.9 \%$ of the H CPR doctors, $47.1 \%$ of the M CPR doctors and $28.6 \%$ of the L CPR doctors. These differences were, however, not statistically significant.

\section{Focus on the Campania region (M CPR) experience: differences and similarities among $\mathrm{CC}, \mathrm{UH}$ and $\mathrm{GH}$}

Most of the results are comparable with the national ones. The majority of Campanian doctors assessed CPs for COVID-19 symptoms by telephone consultation on the day before and on the day of clinic appointment through physical examinations in dedicated areas $(\mathrm{CC}=60 \%$, $\mathrm{UH}=83.3 \%, \mathrm{GH}=62.5 \%$ ). High consensus about ICI interruptions in case of suspected COVID-19 CPs was registered, with only $5.3 \%$ of physicians declaring to continue ongoing ICIs without delays. Moreover, $60 \%, 41.7 \%$ and $25 \%$ of responders (respectively from CC, $\mathrm{UH}$ and $\mathrm{GH}$ ) did not perform any additional diagnostic examinations. As national results, the most favorite diagnostic work-up, where required, included ICI interruption, thorax CT scan and blood tests, as previously described (CC $=10 \%$, $\mathrm{UH}=8.3 \%, \mathrm{GH}=31.3 \%)$. Telemedicine was broadly used for both patients in follow-up after completing ICI adjuvant treatment or achieving complete response $(\mathrm{CC}=80 \%$, $\mathrm{UH}=100 \%, \mathrm{GH}=62.5 \%$ ). Screening test for COVID-19 was adopted for CPs candidate for adjuvant ICIs ( $\mathrm{CC}=80 \%$, $\mathrm{UH}=66.7 \%, \mathrm{GH}=81.3 \%$ ), as well as for metastatic patients ( $\mathrm{CC}=80 \%, \mathrm{UH}=100 \%, \mathrm{GH}=87.5 \%)$, therefore avoiding ICI start delays. Several physicians had CPs positive for SARS-CoV-2 (less than 10) while on treatment with ICIs $(\mathrm{CC}=50 \%, \mathrm{UH}=50 \%, \mathrm{GH}=6.3 \%$; $\mathrm{p}=0.017)$. Routinely, $40 \%, 33.3 \%$ and $50 \%$, of CC, UH and GH doctors, respectively, would not use the schedule interval as criterion of choice for ICI treatment. Of note, none of the CC doctors gave preference for shorter interval schedules. However, as for national results, an ICI with a longer schedule interval was the favorite option for $70 \%, 66.7 \%$ and $81.3 \%$ of $\mathrm{CC}, \mathrm{UH}$ and $\mathrm{GH}$ responders, respectively, during the COVID-19 pandemic. There was also almost unanimous consensus on not modifying the recommended steroid dose in case of ir-AEs $(\mathrm{CC}=100 \%, \mathrm{UH}=100 \%, \mathrm{GH}=93.8 \%)$. The majority of doctors did not change ICIs in favor of chemotherapy $(\mathrm{CC}=100 \%, \mathrm{UH}=83.3 \%, \mathrm{GH}=87.5 \%)$, as well as in favor of targeted therapy, when applicable $(\mathrm{CC}=80 \%, \mathrm{UH}=66.7 \%, \mathrm{GH}=100 \%)$; this last result was statistically different $(p=0.05)$. In terms of supportive treatment, there was agreement for using the G-CSF only in cases of febrile neutropenia ( $\mathrm{CC}=70 \%, \mathrm{UH}=87.5 \%$, $\mathrm{GH}=66.7 \%$ ), with no substantial changes during the COVID-19 pandemic. Almost unanimous agreement was detected on not delaying ICI start in lung CPs (CC=100\%, $\mathrm{UH}=83.3 \%, \mathrm{GH}=100 \%$ ). Finally, a statistically significant difference was found in surgical treatment delays among different contexts $(\mathrm{CC}=10 \%, \mathrm{UH}=75 \%, \mathrm{GH}=37.5 \%$; $\mathrm{p}=0.008$ ).

\section{DISCUSSION}

Young Italian oncologists' experience: ensuring high quality of care in the midst of the COVID-19 pandemic

The WHO research agency (IARC) estimated 18.1 million new cancer cases with 9.6 million cancer deaths in $2018 .^{10}$ As of May 8, 2020, over 3.0 million cases of COVID-19 and more than 250,000 related deaths have been reported ${ }^{1}$ : these numbers tell the unrestrainable progression of two shocking illnesses affecting humans with reciprocal implications. ${ }^{11}$ While cancer is a long-lasting health challenge for thousands of physicians and entire health systems worldwide, COVID-19 has overwhelmed the healthcare system rapidly and with unprecedented virulence; therefore, the sum of both diseases can have devastating outcomes. As a result, medical oncologists are facing a very hard time during the COVID-19 pandemic, shacked among reassessing standards of cancer care, adapting day-by-day healthcare system and acknowledging the paradoxical need to keep patients away from the healthcare facilities and minimize the admissions. Several recommendations from cancer societies and expert opinions have been promptly developed to guide and to find practical solutions for the oncology clinic daily practice. ${ }^{12}$ However, despite the prospering number of recent publications on this topic, ${ }^{6810}$ there is still a great deal of uncertainty about COVID-19 and its effects on CPs. A recent meta-analysis of 11 studies revealed that the overall pooled prevalence of CPs with COVID-19 was $2.0 \%$, with higher risk of severe events such as increased percentage of CPs admitted to intensive care unit who required invasive ventilation, or died, as compared with non-oncologic patients. ${ }^{13}$ Recently, the experience on COVID-19 and cancer from an oncology hub institution in Milan has been reported; of note, only two out of nine COVID-19positive CPs presented with severe illness receiving in-patient care, and none of the two patients receiving immunotherapy experienced severe adverse outcomes. ${ }^{14}$ These data provide preliminary insights into the correlation between COVID-19 and cancer; however, data regarding COVID-19 impact on CPs undergoing ICIs are still lacking and the big deal of postponing or changing treatments or treatment schedule without compromising their efficacy, especially for ICI high responsive malignancies such as melanoma and lung cancer, is a matter of great interest in the oncological community. Our study represents the first snapshot of the measures adopted by young Italian medical oncologists to ensure the best quality treatment to CPs without jeopardizing the success of ICIs. From our study, we can conclude that, while the COVID-19 hurricane has prompted the re-organization of the healthcare structures, called to re-adapt all their 
areas to ensure physical distancing and protection with specific equipment, the management strategies for CPs treated with immunotherapy have largely remained intact among different centers and regions that participated to our survey. Indeed, there was an almost unanimous consent of not delaying immunotherapy in the adjuvant setting as well as for metastatic disease, and at the same time trying to adopt cautionary measures such as triage screening for COVID-19, reduction of the number of in-person accesses to clinic by preferring, when possible, ICIs with longer interval schedule and broad use of telemedicine for patients in follow-up after ICIs. It is of note that there is an almost unanimous consent to screen for COVID-19 symptoms in metastatic patients, therefore avoiding immunotherapy delays. This highlights the inclination of protecting a more fragile category at higher risk of cancer progression and related complications in case of delay of systemic treatment and the general confidence of the young oncological community in the efficacy and safety of immunotherapy. In the same way, the majority of physicians preferred ICIs over the use of chemotherapy or targeted therapy. This large agreement most likely reflects the priority to ensure a high level of oncological assistance for CPs as also suggested by the preferential management in expertise centers for immunotherapy. Interestingly, there was also a large consensus about not modifying the recommended steroid dose in case of ir-AEs. Although emerging reports ${ }^{15} 16$ and previous reviews of outcomes in other viral pneumonias ${ }^{17} 18$ showed that corticosteroids' action, to decrease the host inflammatory responses in the lungs, may be overshadowed by adverse effects, such as delayed viral clearance and increased risk of secondary infection, no randomized clinical trials have clearly demonstrated the harms and lack of proven benefit for steroid use in patients with COVID-19. Conversely, the benefit of steroid administration for ir-AE management has been widely proven. ${ }^{19}$ As a result, the majority of responders feel confident to not modify steroid dose in case of ir-AEs.

Finally, the discrepancy about the COVID-19 screening modality before the appointment in the clinic, with only telephone check on the day before for the L CPR, may be related only to the low positive cases registered in that region. COVID-19 clean areas do not reflect the majority of responders in Italy since different hospital contexts were included in the survey.

\section{Campania experience: ensuring high-quality care maintaining medium COVID-19 prevalence in the first Italian region for population density}

The National Institute of Health reports each year in Campania (comprising Naples, the third largest city in Italy, and the provincial capitals of Salerno, Caserta, Avellino and Benevento) 398 new cases of cancer per 100,000 inhabitants for the male sex versus a national rate of 336 per 100,000 inhabitants. ${ }^{20}{ }^{21}$ Of note, Campania is the third most populous Italian region (after Lombardia and Lazio) with over 5.8 million residents within 13,671 $\mathrm{km}^{2}$ and the first for population density with 1499 inhabitants per square kilometer. ${ }^{22}$ As a consequence, during the Italian COVID-19 emergency, the Campania Region Health Committee has pursued the great challenge to control the virus spread in such a high-risk territory, trying to maintain high-quality level of assistance and to protect the most fragile populations, including the oncological one. Basically, considering the pre-existing hub-andspoke scheme of Rete Oncologica Campana (ROC Oncology Network of Campania Region), founded with the Regional Act $n^{\circ} 98$ in 2016, ${ }^{23}$ for ensuring equity of access to the local oncological users, and for integrating regional health facilities, ${ }^{24}$ during COVID-19 time, Campania Region restructured the service delivery by maintaining the ROC network-based model and re-adapting some existing health structures as COVID-19 preferential hubs. Recently, also a dedicated COVID-19 center for SARS-CoV-2-positive CPs was assembled at Ospedale del Mare, in Naples. With the support of territorial medicine, based on primary healthcare, and the large use of telemedicine, the challenging aim to contain the COVID-19 infection, while maintaining essential healthcare, seems to have been achieved. Indeed, Campania remains as a medium COVID-19 prevalence region, with few positive cases among CPs reported so far. All the multidisciplinary referral oncological centers (CORP), identified by the ROC and included in our survey, have promptly re-organized the clinical daily practice with triage screening procedures in line with the national directions. Regarding the issue of CPs treated with immunotherapy, addressed specifically by our survey, the Campanian results are very similar to the national ones, highlighting the big effort of all the oncological communities to deliver high standard care also during emergency period. Few responses were statistically different among $\mathrm{CC}, \mathrm{UH}$ and $\mathrm{GH}$. Very intriguingly, $\mathrm{GH}$, which are included in the ROC with equal volume of CPs compared with UH and CC, had the lowest rate of positive CPs treated with ICIs, probably due to the faster activation of COVID-19 clean areas. Of note, there was also a higher percentage of Campanian oncologists who consider targeted therapy in place of ICIs, maybe due to the higher number of physicians committed to melanoma cancer enrolled in the subanalysis for Campania region.

\section{CONCLUSIONS}

Despite the limited number of responders and the lack of participants from some Italian regions, the results of our study highlight, for the first time, the common efforts of Italian young oncologists, who are daily involved in the management of CPs treated with ICIs, in maintaining high standard treatments during the COVID-19 pandemic. As the oncology community is daily facing the evolving COVID-19 global health emergency and trying to fill the gap of scientific and clinic data, it is imperative that clinical practice data-driven decisions are shared by those caring for patients. 


\section{RECOMMENDATIONS}

We have summarized the viewpoint of the responders to this survey in a brief list of recommendations that we believe would be of help for CP management with ICIs during the COVID-19 pandemic. This is not a formally developed guideline, but rather reflects the opinion of a robust number of Italian oncologists daily involved in delivering immunotherapy in CPs.

- CPs treated with ICIs should be preferentially assessed for COVID-19-related symptoms by telephone consultation on the day before the hospital appointment and on the day of clinic appointment through physical examinations in dedicated areas.

- Telemedicine should be applied to both CPs who achieved complete response after ICI treatment and patients who finished ICI treatment with adjuvant purpose.

- Triage screening for COVID-19 should be performed for both patients with metastatic disease and patients who are starting immunotherapy in adjuvant setting, avoiding any delays.

- When applicable, the clinicians should adopt the longest schedule of ICIs to reduce the monthly hospital admissions.

- ICIs should be withheld until an active SARS-CoV-2 infection has resolved or has been ruled out with highly accurate molecular testing, as per international guidelines.

- In case of adverse events, the physicians should follow the current recommendation for ICI-related adverse event management according to toxicity grade, without reducing the dose of steroids.

- In case of non-febrile neutropenia, physicians should not prescribe G-CSF, as per clinical practice.

- CPs treated with ICIs should be referred preferentially to immunotherapy expertise centers.

- ICIs in patients with lung cancer should not be avoided for fear of potential lung toxicity and given the high lung tropism of SARS-CoV-2 virus and its risk of ARDS in asymptomatic and/or coronavirus-free patients.

\section{Author affiliations}

${ }^{1}$ Oncology Unit, Ospedale del Mare, Napoli, Campania, Italy

${ }^{2}$ Department of Clinical Medicine and Surgery, Università degli Studi di Napoli

Federico II and CRCTR Coordinating Rare Tumors Reference Center of Campania Region, AOU Federico II, Napoli, Italy

${ }^{3}$ Unit of Melanoma, Cancer Immunotherapy and Development Therapeutics, Istituto Nazionale Tumori IRCCS Fondazione Pascale, Napoli, Campania, Italy

${ }^{4}$ Clinical Studies, The Institute of Cancer Research and the Royal Marsden NHS

Foundation Trust, London, UK

${ }^{5}$ CRCTR Coordinating Rare Tumors Reference Center of Campania Region, AOU

Federico II, Napoli, Campania, Italy

${ }^{6}$ Biostatistics Unit, IRCCS Regina Elena National Cancer Institute, Roma, Lazio, Italy

${ }^{7}$ Medical Oncology Unit, Department of Onco-Hematology, IRCCS-CROB Referral

Cancer Center of Basilicata, Rionero in Vulture, Basilicata, Italy

${ }^{8}$ Oncology Unit, Ospedale Ferdinando Veneziale, Isernia, Molise, Italy

${ }^{9}$ Department of Urology and Gynecology, Istituto Nazionale Tumori IRCCS

Fondazione Pascale, Napoli, Campania, Italy

${ }^{10} \mathrm{Abdominal}$ Oncology Unit, Istituto Nazionale Tumori IRCCS Fondazione Pascale,

Napoli, Campania, Italy

${ }^{11}$ Medical Oncology Unit, University of Pisa, Pisa, Toscana, Italy
${ }^{12}$ Oncology Unit, Ospedale del Mare, Napoli, Italy

${ }^{13}$ Department of Radioterapia, Istituto Nazionale Tumori IRCCS Fondazione Pascale, Napoli, Campania, Italy

${ }^{14}$ Oncology Unit, San Rocco Hospital, Sessa Aurunca, Campania, Italy

${ }^{15}$ Oncology Unit, Ospedale Della Murgia, Bari, Puglia, Italy

${ }^{16}$ U.O.C. Oncologia, Azienda Ospedaliera dei Colli, Monaldi Hospital, Napoli,

Campania, Italy

${ }^{17}$ Department of Medical Oncology, AORN "A. Cardarelli", Napoli, Campania, Italy

${ }^{18}$ Oncology Unit, Villa Scassi Hospital, Genova, Italy

${ }^{19}$ Oncology, Department of Precision Medicine, Università della Campania "L.

Vanvitelli", Napoli, Campania, Italy

${ }^{20}$ Medical Oncology Department, Istituto Scientifico Romagnolo per lo Studio e la

Cura dei Tumori (IRST) IRCCS, Meldola, Emilia-Romagna, Italy

${ }^{21}$ Oncology Unit, Sant'Ottone Frangipane Hospital, Avellino, Campania, Italy

${ }^{22}$ Oncology Unit, Sant'Anna e San Sebastiano, Caserta, Campania, Italy

${ }^{23}$ Breast Unit, Istituto Nazionale Tumori IRCCS Fondazione Pascale, Napoli,

Campania, Italy

${ }^{24}$ Department of Clinical Medicine and Surgery, Oncology Unit, Università degli Studi

di Napoli Federico II, Napoli, Campania, Italy

${ }^{25}$ Oncology Unit, Gemelli Molise s.p.a, Campobasso, Molise, Italy

${ }^{26}$ Division of Medical Oncology, "San Giuseppe Moscati" Hospital, Avellino,

Campania, Italy

${ }^{27}$ Oncology Unit, SS Antonio e Biagio e Cesare Arrigo Hospital, Alessandria,

Piemonte, Italy

${ }^{28}$ Department of Medical Oncology, Fondazione IRCCS Istituto Nazionale dei Tumori,

Milano, Lombardia, Italy

${ }^{29}$ Department of Oncology, University of Verona, Verona, Veneto, Italy

${ }^{30}$ Department of Medical Oncology, Santa Chiara Hospital, Trento, Trentino Alto Adige, Italy

${ }^{31}$ UOC Oncologia Medica, Ospedali Riuniti Villa Sofia Cervello, Palermo, Sicilia, Italy

${ }^{32}$ Department of Oncology, Azienda Sanitaria Universitaria Integrata del Friuli

Centrale, Udine, Friuli Venezia Giulia, Italy

${ }^{33}$ Thoracic Medical Oncology, Istituto Nazionale Tumori IRCCS Fondazione Pascale, Napoli, Campania, Italy

${ }^{34}$ Vancouver Prostate Centre, Department of Urologic Sciences, University of British Columbia, Vancouver, BC, Canada and British Columbia Cancer Agency-Vancouver Center-Department of Medicine, Division of Medical Oncology, University of British Columbia, Vancouver, British Columbia, Canada

${ }^{35}$ Oncology Unit, Ospedale Sacro Cuore di Gesù Fatebenefratelli, Benevento, Campania, Italy

${ }^{36}$ Institute of Research on Genetics and Biomedicine (IRGB), National Research Council (CNR), Sassari, Sardegna, Italy

${ }^{37}$ Department of Medicine, Surgery and Dentistry "Scuola Medica Salernitana",

Oncology Unit, University of Salerno, Baronissi, Campania, Italy

${ }^{38}$ U.O.C. Pneumologia Oncologica, Azienda Ospedaliera dei Colli, Monaldi Hospital, Naples, Campania, Italy

${ }^{39}$ Veneto Institute of Oncology IOV-IRCCS, Padova, Veneto, Italy

${ }^{40}$ Medical Oncology Unit, ASL CN2, Alba, Piemonte, Italy

${ }^{41}$ Medical Oncology Unit, Fondazione IRCCS Giovanni Paolo II, Bari, Puglia, Italy

${ }^{42}$ Medical Oncology Unit, University Hospital Modena, Modena, Emilia Romagna, Italy

${ }^{43}$ Oncology Unit, Fondazione Istituto San Raffaele G Giglio di Cefalu, Cefalu, Sicilia, Italy

${ }^{44}$ Division of Early Drug Development for Innovative Therapies, European Institute of Oncology IRCCS, Milano, Lombardia, Italy

${ }^{45}$ Medical Oncology 1 Unit, IRCCS Regina Elena National Cancer Institute, Rome, Lazio, Italy

${ }^{46}$ Oncology Division, ASL San Felice a Cancello, Caserta, Campania, Italy

${ }^{47}$ Department of Surgery and Cancer, Imperial College, London, UK

${ }^{48}$ Oncology Unit, Università degli Studi di Verona, sede Borgo Roma, Verona, Veneto, Italy

${ }^{49}$ Medical Oncology Department, AOUI di Verona, Verona, Veneto, Italy

Contributors The authors listed below have made substantial contributions to the intellectual content of the paper in the various sections described below: conception and design: MO. Acquisition of data: MO, PR, MT, AP, AL, AA, FB, DB, BV, BG, CG, FC, CD, CA, CR, DFS, DFM, DPP, IDS, DSA, DFR, DLV, FA, PF, LF, PG, AMG, LM, MAL, MV, AM, MS, VM, CM, MM, MM, MAM, MB, PI, PS, AP, PL, PF, PE, PV, RV, MR, RA, RA, SM, SA, ES, ASi, SM, TarP, TavP, TF, TV, CT, VV, VS, VJ, MGV, FV, VC, ZF, Zl. Analysis and 
interpretation of data: M0, PR. Drafting of the manuscript: MO, PR. Critical revision of the manuscript for important intellectual content: PG, BD, AZ, CvA, DT, LN, CMDC FM, GC, NF, SG, PM, MG. Statistical analysis: DG, MO. Administrative, technical or material support: MT, MC. Supervision: PAA, SDP, FC, VM, FP, SP, DLM, VC, AM, GP, SP, MAM, MA, CG.

Funding The authors have not declared a specific grant for this research from any funding agency in the public, commercial or not-for-profit sectors.

Competing interests None declared.

Patient consent for publication Not required.

Ethics approval All procedures performed in studies involving human participants were in accordance with the ethical standards of the institutional and/or national research committee and with the 1964 Helsinki declaration and its later amendments or comparable ethical standards. For this survey report, formal consent is not required.

Provenance and peer review Not commissioned; externally peer reviewed.

Data availability statement All data relevant to the study are included in the article or uploaded as online supplemental information. The submitting author will provide the data or will cooperate fully in obtaining and providing the data on which the manuscript is based for examination by the editors or their assignees.

Open access This is an open access article distributed in accordance with the Creative Commons Attribution Non Commercial (CC BY-NC 4.0) license, which permits others to distribute, remix, adapt, build upon this work non-commercially, and license their derivative works on different terms, provided the original work is properly cited, appropriate credit is given, any changes made indicated, and the use is non-commercial. See http://creativecommons.org/licenses/by-nc/4.0/.

\section{ORCID iDs}

Margaret Ottaviano http://orcid.org/0000-0001-9589-0808

Valeria Merz http://orcid.org/0000-0002-2120-1923

Alessandro Morabito http://orcid.org/0000-0002-1319-9608

Angelica Petrillo http://orcid.org/0000-0001-5489-5733

Paolo Antonio Ascierto http://orcid.org/0000-0002-8322-475X

\section{REFERENCES}

1 The World Health Organization (WHO). Coronavirus disease (COVID-19) pandemic. Available: https://www.who.int/emergencies/ diseases/novel-coronavirus-2019 [Accessed 8 May 2020]

2 The World Health Organization (WHO). Health emergency dashboard. Available: https://experience.arcgis.com/experience/ 685d0ace521648f8a5beeeee1b9125cd

3 Lazzerini M, Putoto G. COVID-19 in Italy: momentous decisions and many uncertainties. Lancet Glob Health 2020;8:e641-2.

4 Zhou F, Yu T, Du R, et al. Clinical course and risk factors for mortality of adult inpatients with COVID-19 in Wuhan, China: a retrospective cohort study. Lancet 2020;395:1054-62.
5 Liang W, Guan W, Chen R, et al. Cancer patients in SARSCoV-2 infection: a nationwide analysis in China. Lancet Oncol 2020;21:335-7.

6 Desai A, Warner J, Kuderer N, et al. Crowdsourcing a crisis response for COVID-19 in oncology. Nat Cancer 2020;1:473-6.

7 Bersanelli M. Controversies about COVID-19 and anticancer treatment with immune checkpoint inhibitors. Immunotherapy 2020;12:269-73.

8 Ottaviano M, De Placido S, Ascierto PA. Recent success and limitations of immune checkpoint inhibitors for cancer: a lesson from melanoma. Virchows Arch 2019;474:421-32.

9 Ascierto PA, Addeo R, Cartenì G, et al. The role of immunotherapy in solid tumors: report from the Campania Society of Oncology Immunotherapy (SCITO) meeting, Naples 2014. J Transl Med 2014;12:291.

10 Lewis MA. Between Scylla and Charybdis - oncologic decision making in the time of Covid-19. N Engl J Med 2020;382:2285-7.

11 Blandino G. Cancer at the time of the COVID-19 hurricane. J Exp Clin Cancer Res 2020;39:74.

12 Italian Ministry of Health. Recommendations for the management of hematology and oncology patients during the COVID-19 public health emergency. Available: http://www.trovanorme.salute.gov.it/ norme/renderNormsanPdf

13 Desai A, Sachdeva S, Parekh T, et al. COVID-19 and cancer: lessons from a pooled meta-analysis. JCO Glob Oncol 2020;6:557-9.

14 Trapani D, Marra A, Curigliano G. The experience on coronavirus disease 2019 and cancer from an oncology hub institution in Milan, Lombardy Region. Eur J Cancer 2020;132:199-206.

15 Abid MB, Mughal M, Abid MA. Coronavirus disease 2019 (COVID-19) and immune-engaging cancer treatment. JAMA Oncol 2020. doi:10.1001/jamaoncol.2020.2367. [Epub ahead of print: 20 May 2020].

16 Russell CD, Millar JE, Baillie JK. Clinical evidence does not support corticosteroid treatment for 2019-nCoV lung injury. Lancet 2020;395:473-5.

17 Wong SSY, Yuen K-Y. The management of coronavirus infections with particular reference to SARS. J Antimicrob Chemother 2008;62:437-41.

18 Chihrin S, Loutfy MR. Overview of antiviral and anti-inflammatory treatment for severe acute respiratory syndrome. Expert Rev Anti Infect Ther 2005;3:251-62.

19 Friedman CF, Proverbs-Singh TA, Postow MA. Treatment of the immune-related adverse effects of immune checkpoint inhibitors: a review. JAMA Oncol 2016;2:1346-53.

20 I numeri del cancro in Italia. AIOM 2019.

21 Fusco M, De Angelis R, Senatore G, et al. Estimates of cancer burden in Campania. Tumori 2013;99:374-81.

22 Annuario Statistico Italiano 2019. Available: https://www.istat.it/it/ files/2019/12/Asi-2019.pdf

232018 DECRETO N. 89 DEL 05.11.2018. BURC. Available: http://burc regione.campania.it/eBurcWeb/directServlet?DOCUMENT

24 De Placido S, Bracale U, Pacelli R, et al. A new strategy for a high tumour burden region: the Campania oncological network. Transl Med UniSa 2020;21:59-60. 